\title{
Lupus anticoagulant: clinical significance in anticardiolipin positive patients with systemic lupus erythematosus
}

\author{
N J McHugh, D A H Moye, I E James, M Sampson, P J Maddison
}

\begin{abstract}
The significance of anticardiolipin antibodies and the lupus anticoagulant was studied in $\mathbf{5 8}$ consecutive patients with systemic lupus erythematosus. On 85 occasions serum IgG and IgM anticardiolipin antibodies were measured by an enzyme linked immunosorbent assay (ELISA), and simultaneous plasma samples tested for lupus anticoagulant activity. The most significant association with clinical events (previous thrombosis or thrombocytopenia occurring in 11/58 patients) was with prolonged tissue thromboplastin inhibition time (TTIT) followed by prolonged kaolin cephalin clotting time (KCCT) then raised IgG anticardiolipin antibody concentrations and dilute Russell's viper venom time. Although IgG anticardiolipin antibodies or KCCT were the most sensitive tests in identifying this group, the TTIT was the most specific $(98 \%)$. Nine patients were IgG anticardiolipin antibody positive and lupus anticoagulant negative, of whom one had thrombocytopenia but none had thrombosis. The presence of a lupus anticoagulant in anticardiolipin antibody positive patients increases specificity for certain adverse clinical events.
\end{abstract}

Anticardiolipin antibodies identify a subgroup of patients with systemic lupus erythematosus with recurrent arterial and venous thrombosis, ${ }^{1}$ thrombocytopenia, ${ }^{2}$ and recurrent pregnancy loss. ${ }^{3} 4$ Other clinical features occurring in this group include cerebrovascular disease and livedo reticularis. ${ }^{5}$ Patients with high IgG anticardiolipin antibody concentrations seem most at risk, ${ }^{47}$ though occasionally patients with systemic lupus erythematosus may have high concentrations of anticardiolipin antibodies over many years without any of these complications. ${ }^{8}$ Also, anticardiolipin antibodies may be found in a variety of other infectious, malignant, and drug related conditions. ${ }^{9}$ More specific factors may need to be present to account for the pathogenetic events with which anticardiolipin antibodies are associated in systemic lupus erythematosus. The ability of anticardiolipin antibodies to interfere with phospholipid dependent coagulation may represent such a factor.

Lupus anticoagulants are immediate acting acquired inhibitors of coagulation. It has been reported that their presence is more specific for thrombotic or adverse obstetric events occurring in systemic lupus erythematosus than the presence of anticardiolipin antibodies ${ }^{1011}$ and vice versa. ${ }^{12} \mathrm{~A}$ variety of coagulation tests have been used for the detection of the lupus anticoagulant. ${ }^{13-15}$ The tests show variable sensitivity or specificity depending on the immunoglobulin class, the type of phospholipid reagents, and the instrumentation used. We used three different phospholipid dependent clotting assays to screen for the presence of a lupus anticoagulant in 58 consecutive patients with systemic lupus erythematosus. We studied their relation with each other and with anticardiolipin antibodies and their individual ability in comparison with the presence of anticardiolipin antibodies to identify lupus patients with thrombotic events or thrombocytopenia.

\section{Patients and methods}

PATIENTS

Fifty eight consecutive patients (51 female, seven male) fulfilling American Rheumatism Association criteria for systemic lupus erythematosus ${ }^{16}$ attending a connective tissue disease clinic were studied. Three other patients with thromboembolic disease who were receiving anticoagulants were excluded from the study because of the confounding effect of treatment on their coagulation tests. Paired serum and plasma samples were obtained on 87 visits as 23 patients were studied on more than one occasion. Results from only the first sampling were used for analysis of clinical associations.

\section{ANTICARDIOLIPIN ANTIBODIES}

Anticardiolipin antibodies were measured by an enzyme linked immunosorbent assay (ELISA) as previously described ${ }^{6}$ validated against international workshop standards. ${ }^{17}$ Serum samples were tested in duplicate, and on each ELISA plate three standards covering a range of positivity and five normal serum samples were used to construct a standard curve. Results were expressed as units, each unit equivalent to one standard deviation (SD) above the mean of 100 blood bank serum samples previously tested. Any result above 2 SD was considered abnormal. For IgG anticardiolipin antibodies 2-5 SD was defined as low, 5-20 SD as moderate, and above 20 as high positivity. For IgM anticardiolipin antibodies 2-5 SD was defined as low, 5-10 as moderate, and above 10 as high positivity. Further validation of our ELISA was obtained by participation in an international study in which multiple exchange of serum samples between laboratories took place. ${ }^{18}$ Our units are equivalent to proposed international units (GPL and MPL) as follows: for IgG anticardiolipin 
antibodies $2 \mathrm{SD}=9 \mathrm{GPL}, 5 \mathrm{SD}=24 \mathrm{GPL}$, $20 \mathrm{SD}=100 \mathrm{GPL}$; for IgM anticardiolipin antibodies $2 \mathrm{SD}=6 \mathrm{MPL}, 5 \mathrm{SD}=25 \mathrm{MPL}, 10 \mathrm{SD}=$ $55 \mathrm{MPL}$.

\section{LUPUS ANTICOAGULANT}

Whole blood was collected into Becton Dickinson container bottles containing 1/10 volume of trisodium citrate. As lupus anticoagulant activity seems to be less evident in the presence of platelets the blood was centrifuged at $2500 \mathrm{~g}$ for 20 minutes at $4^{\circ} \mathrm{C}$ to obtain platelet free plasma. The plasma was stored at $-20^{\circ} \mathrm{C}$ until tested.

In this study three phospholipid dependent coagulation tests were used. The tissue thromboplastin inhibition test (TTIT) is a modification of the one stage prothrombin time, which is a measure of the extrinsic clotting system. The kaolin cephalin clotting time (KCCT) is a modification of the activated partial thromboplastin time and is a measure of the intrinsic clotting system. The dilute Russell's viper venom test (RVVT) is independent of the intrinsic and extrinsic systems; Russell's viper venom activates factor $X$ directly in the presence of phospholipid and calcium ions. In both the KCCT and the RVVT the source of phospholipid is cephalin.

\section{KAOLIN CEPHALIN CLOTTING TIME}

Patient's plasma $(0 \cdot 1 \mathrm{ml})$ was incubated with $0.1 \mathrm{ml}$ of Bell and Alton cephalin at standard concentration, and $0.1 \mathrm{ml}$ of $0.5 \%$ light kaolin in Owen's buffer for three minutes at $37^{\circ} \mathrm{C}$. Calcium chloride $(0.1 \mathrm{ml}, 0.025 \mathrm{~mol} / \mathrm{l})$ was then added and the clotting time recorded. The presence of a lupus anticoagulant was indicated by prolongation of the KCCT, not corrected in a 1:1 mixture of patient's and pooled normal plasma. The 1:1 mixture was tested at 10 and 60 minutes to show that the inhibitory effect was not progressive, unlike the specific factor inhibitors.

\section{RUSSELL'S VIPER VENOM TIME}

This was performed by an adaptation of the method of Austin and Rhymes. ${ }^{19}$ The test reagent was prepared by diluting $0.2 \mathrm{ml}$ of a $1 / 1000$ solution of Russell's viper venom with $3 \mathrm{ml}$ of a $1 / 8$ dilution of cephalin. This combination was found to give a RVVT of 22 seconds with normal plasma. Patient's plasma $(0.1 \mathrm{ml})$ was incubated with $0.1 \mathrm{ml}$ of reagent at $37^{\circ} \mathrm{C}$ for 30 seconds. Calcium chloride $(0.1 \mathrm{ml}$, $0.025 \mathrm{~mol} / \mathrm{l}$ ) was then added and the clotting time recorded. The presence of a lupus anticoagulant was indicated by prolongation of the KCCT, not corrected in a $1: 1$ mixture of patient's and pooled normal plasma.

TISSUE THROMBOPLASTIN INHIBITION TEST

This was performed by an adaptation of the method of Schleider et al. ${ }^{20}$ A 1/1000 dilution of Manchester thromboplastin $(0.01 \mathrm{ml})$ in $0.9 \%$ $\mathrm{NaCl}$ was incubated with $0.1 \mathrm{ml}$ of patient's plasma for five minutes. Calcium chloride $(0 \cdot 1$ $\mathrm{ml}, 0.025 \mathrm{~mol} / \mathrm{l}$ ) was then added and the clotting time recorded. The ratio of the patient's clotting time to the clotting time of normal pooled plasma was calculated. The presence of a lupus anticoagulant was indicated by a ratio of $>1 \cdot 3$, not corrected in a 1:1 mixture of patient's and pooled normal plasma.

All the above tests were performed on a Roce Cobas fibrocoagulometer.

\section{STATISTICAL ANALYSIS}

Spearman's rank correlation and the $\chi^{2}$ test were used as indicated.

\section{Results}

ANTICARDIOLIPIN ANTIBODY AND LUPUS ANTICOAGULANT POSITIVITY

Seventeen patients had an initial increase of IgG anticardiolipin antibodies, 10 in the moderate range and seven in the low range. Five of these patients and four others had raised IgM anticardiolipin antibodies (six in the low range). Of the 17 patients with raised IgG anticardiolipin antibody concentrations nine were negative for lupus anticoagulant in all three assays and eight were positive in at least one assay. There was no significant difference in the median IgG anticardiolipin antibody concentration between these last two groups.

Thirteen patients were lupus anticoagulant positive on their first sample in at least one assay. Twelve patients had an abnormal KCCT, eight an abnormal RVVT, and six an abnormal TTIT. Four patients were abnormal in all three clotting assays, another five abnormal in two assays, and four patients abnormal in one assay alone.

\section{CORRELATION BETWEEN ANTICARDIOLIPIN} ANTIBODIES AND COAGULATION ASSAYS

There was a highly significant correlation (Spearman's) between anticardiolipin antibody concentrations and all assays used for measuring lupus anticoagulant with the exception of $\operatorname{IgM}$ anticardiolipin antibodies and the KCCT, which just failed to reach significance (table 1). Similarly, there was a highly significant association between the individual coagulation assays.

\section{SERIAL ANTICARDIOLIPIN ANTIBODY}

CONCENTRATIONS AND LUPUS

ANTICOAGULANT MEASUREMENTS

Twenty three patients had further paired serum and plasma samples taken at a later date and

Table 1 Relation between anticardiolipin antibodies $(a C L)$ and coagulation assays

\begin{tabular}{|c|c|c|c|c|}
\hline & $\operatorname{Ig} G a C L$ & IgM $a C L$ & KCCT & $T T I T$ \\
\hline IgM aCL & + & & & \\
\hline & $\begin{array}{l}+ \\
+\end{array}$ & $\begin{array}{l}\text { NS } \\
+\end{array}$ & + & \\
\hline RVVT* $^{*}$ & + & + & + & + \\
\hline
\end{tabular}

$+=p<0.001$ (Spearman's rank correlation); NS = not significant . plastin $=$ kaolin cephalin clotting time; TTIT $=$ tissue thrombo- 

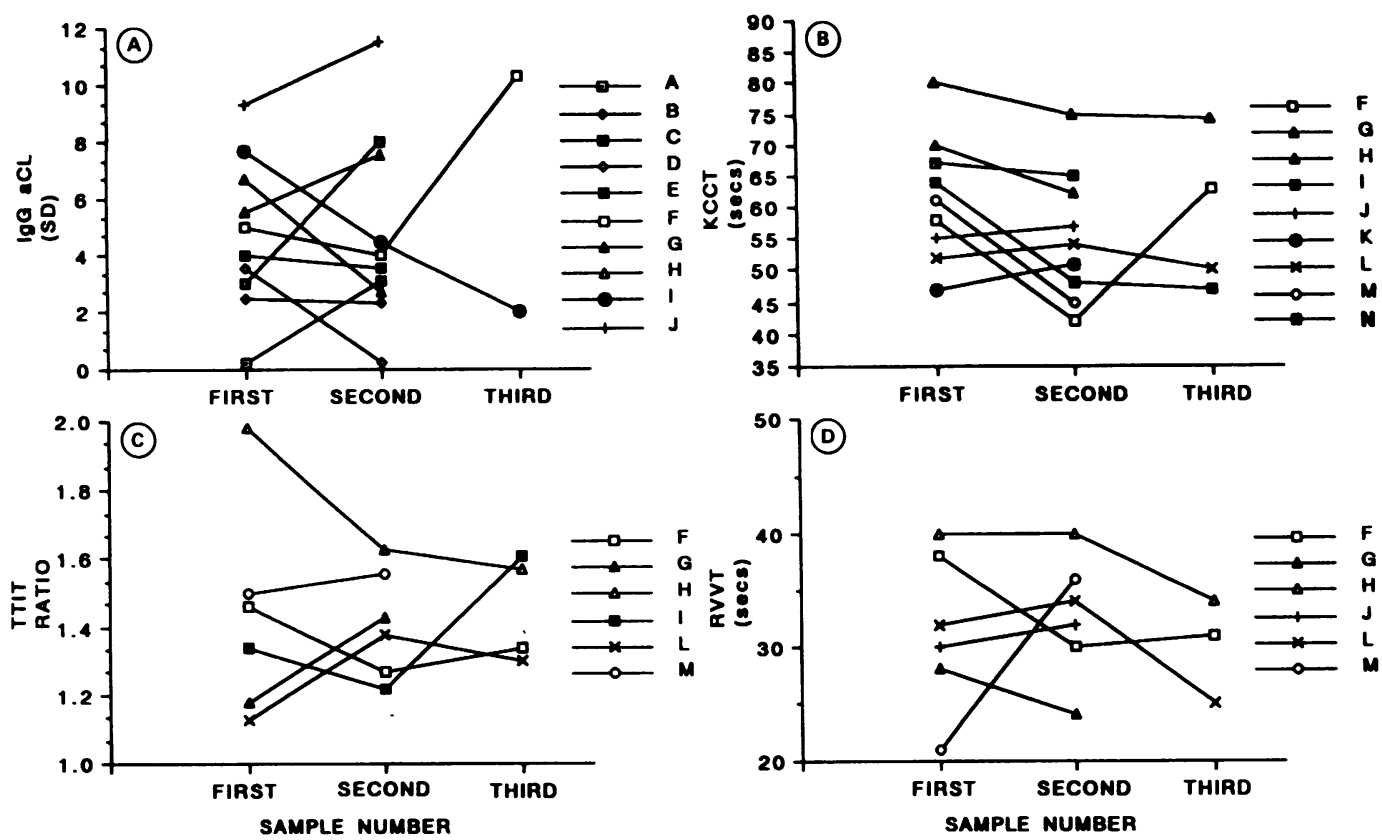

Results of serial measurements of $(A) I g G$ anticardiolipin antibodies $(a C L) ;(B)$ kaolin cephalin clotting time $(K C C T)$ : (C) tissue thromboplastin inhibition test ratio (TTIT); (D) Russell's viper venom time (RVVT).

four of these were also bled on a third occasion. The figure shows the serial results for those patients positive in any one of the IgG anticardiolipin antibody or coagulation tests. Nine patients who were IgG anticardiolipin antibody positive on the first occasion all remained positive (figure A). Only one of the other 14 patients (patient A) became IgG anticardiolipin antibody positive and this at low levels. The relation between disease activity, pregnancy, and treatment and anticardiolipin antibody concentrations in a larger number of patients over a longer period is the subject of a separate study.

Nine of the 23 patients studied serially had an abnormal KCCT on at least one occasion (figure B), six of these nine had at least one abnormal TTIT (figure C), and six of these nine had at least one abnormal RVVT (figure D). Most patients who were lupus anticoagulant positive by one assay in the initial sample remained positive by that respective assay in the second or third samples. Conversely, 14 of the 23 patients studied serially were lupus anticoagulant negative in all three assays on first sampling and remained so on serial samples.

Although there were occasional discordant fluctuations between the IgG anticardiolipin antibody concentrations and the coagulation times most often any variation was in the same direction. IgG anticardiolipin antibody concentrations returned to normal in only one patient (patient $\mathrm{D}$, figure $\mathrm{A}$ ), and this patient had no evidence of a lupus anticoagulant. An initially raised KCCT in three patients became normal. In one patient (patient I, figure B) this corresponded with the start of prednisolone treatment and a fall in the IgG anticardiolipin antibody concentrations and normalisation of the TTIT. In another patient (patient $F$, figure B) this corresponded with an increase of prednisolone dose during a pregnancy and a fall in IgG anticardiolipin antibody concentrations and normalisation of the TTIT. In this patient a third sample taken 12 months after the preg- nancy when the patient was no longer receiving prednisolone showed a return to more abnormal values in these three assays.

\section{THROMBOSIS AND THROMBOCYTOPENIA}

The patients were divided on the basis of the occurrence of adverse features previously described in association with antiphospholipid antibodies. Thus 11 of the 58 patients had a well reported thromboembolic event or a persistent idiopathic thrombocytopenia (platelet count below $120000 \times 10^{9} / 1$ on at least two occasions not related to drug treatment), or both. Four had thrombocytopenia alone, three had had major cerebrovascular accidents, two had thrombocytopenia and a previous pulmonary embolism, one a deep vein thrombosis and a pulmonary embolus, and one a deep vein thrombosis alone.

Detection of raised IgG anticardiolipin antibody concentrations was one of the two most sensitive tests in identifying this group of patients but had the lowest specificity (table 2). This was because of a large number of 'false positive' tests, which also meant a lesser degree of significance compared with the KCCT or the TTIT. Although the specificity improved by

Table 2 Thrombosis or thrombocytopenia, or both (11/58 patients)

\begin{tabular}{|c|c|c|c|}
\hline & $\begin{array}{l}\text { Sensitivity } \\
(\%)\end{array}$ & $\begin{array}{l}\text { Specificity } \\
(\%)\end{array}$ & p Value \\
\hline $\begin{array}{l}\text { IgG aCL }>2 \text { SD } \\
\quad>4 \text { SD } \\
\text { IgM aCL }>2 \text { SD } \\
\text { KCCT* }^{*} \\
\text { TTIT* }^{*} \\
\text { RVVT }^{*} \\
\text { IgG aCL }+ \text { LAC* }^{*}+\end{array}$ & $\begin{array}{r}63 \\
36 \\
9 \\
63 \\
45 \\
27 \\
54\end{array}$ & $\begin{array}{l}79 \\
87 \\
80 \\
91 \\
98 \\
89 \\
96\end{array}$ & $\begin{array}{l}<0.02 \\
\text { NS } \\
\text { NS } \\
<0.001 \\
<0.001 \\
\text { NS } \\
<0.001\end{array}$ \\
\hline
\end{tabular}

${ }^{*} \mathrm{aCL}=$ anticardiolipin antibodies; $\mathrm{KCCT}=\mathrm{kaolin}$ cephalin clotting time; TTIT = tissue thromboplastin inhibition test; $R V V T=$ Russell's viper venom time; $L A C=$ lupus anticoagulant. $\dagger \mathrm{LAC}=$ lupus anticoagulant positive in any one of the three coagulation assays. $\neq \chi^{2}$ Test. 
Table 3 Thrombosis/thrombocytopenia

\begin{tabular}{lll}
\hline & $\begin{array}{l}\text { Positive } \\
(n=11)\end{array}$ & $\begin{array}{l}\text { Negative } \\
(n=47)\end{array}$ \\
\hline IgG aCL*+ve LAC*+vet & 6 & 2 \\
IgG aCL+ve LAC-ve & 1 & 8 \\
IgG aCL-ve LAC+ve & 1 & 4 \\
IgG aCL-ve LAC-ve & 3 & 33 \\
\hline
\end{tabular}

$* \mathrm{aCL}=$ anticardiolipin antibodies; $\mathrm{LAC}=$ lupus anticoagulant. tLAC + ve =lupus anticoagulant positive in any one of three coagulation assays.

increasing the cut off for positivity for IgG anticardiolipin antibodies to $4 \mathrm{SD}$, this was at the expense of a large decrease in sensitivity. Raised IgM anticardiolipin antibodies detected only $9 \%$ of this group of patients.

A prolonged KCCT was as sensitive as increased IgG anticardiolipin antibodies but had the advantage of a lower false positivity rate and hence greater specificity. There was only one patient with an abnormal TTIT who had neither previous thrombosis nor thrombocytopenia, which meant that this was the most specific test, though it had a lower sensitivity. Of the clotting assays the RVVT had the least sensitivity and specificity.

Two patients were both IgG anticardiolipin antibody positive and lupus anticoagulant positive but had no evidence of thrombosis or thrombocytopenia (table 3). There were a larger group of patients, however, with IgG anticardiolipin antibodies alone who had none of these complications.

\section{LUPUS ANTICOAGULANT, ANTICARDIOLIPIN} ANTIBODY NEGATIVE PATIENTS

Three patients were lupus anticoagulant positive on at least one occasion (by all three assays) and were consistently anticardiolipin antibody negative (including patients $M$ and $L$, figures $B$, $C$, and $D$ ). One of these patients had a previous deep vein thrombosis (patient $M$ ), one had severe mitral valve regurgitation which had required replacement and florid livedo reticularis, though had experienced no thromboembolic episodes (patient L), and the third had no unusual features. A fourth patient who had an abnormal RVVT alone (28 seconds) had an illness characterised by non-erosive arthritis and haemolytic anaemia. A fifth patient (patient $\mathbf{N}$, figure B) had an abnormal KCCT alone on two occasions during an uneventful twin pregnancy while she was receiving no drugs.

\section{OTHER CLINICAL FEATURES}

In this study we were unable to find a significant association between the presence of livedo reticularis and either anticardiolipin antibodies or lupus anticoagulant. This may be because a smaller number were studied than in our earlier report ${ }^{6}$ and because the few patients who were receiving anticoagulants were excluded.

Only one patient in this study had recurrent pregnancy loss (patient F), an uncommon feature in our group with systemic lupus erythematosus. ${ }^{21}$ This patient also had a cerebrovascular accident, livedo reticularis, and was both anticardiolipin antibody and lupus anticoagulant positive.

\section{Discussion}

The lupus anticoagulant is an acquired inhibitor of coagulation, which has immunological reactivity towards anionic phospholipid. ${ }^{22}$ It is likely that lupus anticoagulants prolong phospholipid dependent coagulation by acting at the junction of the intrinsic and extrinsic coagulation pathways, interacting with the phospholipid portion of the prothrombinase complex, without inhibiting the activity of specific coagulation factors. This is shown by the fact that the inhibition of in vitro coagulation is immediate and does not increase progressively with incubation time. ${ }^{23}$ In vivo the lupus anticoagulant is associated with thrombosis and thrombocytopenia rather than haemorrhage, probably owing to the extra presence of platelet and endothelial surfaces, but the exact mechanism is uncertain.

The introduction of solid phase assays for measuring antiphospholipid antibodies has allowed more rapid screening of patient groups at risk of harbouring a lupus anticoagulant, and an abundance of reports confirming the aforeseen associations (reviewed in ref 9). Standardisation of the assay for measuring anticardiolipin antibody concentrations may be more easily achievable than the many tests advocated for measuring lupus anticoagulant and facilitates comparison between patient groups. In our study determination of raised IgG anticardiolipin antibody concentrations was an effective though not perfect screening test for the presence of lupus anticoagulant, which was present in eight of 13 such patients. Also raised IgG anticardiolipin antibodies and an abnormal KCCT were the two most sensitive tests in identifying a group of patients with thrombosis or thrombocytopenia. If the presence of a lupus anticoagulant is strongly suspected, however, coagulation studies should be performed in anticardiolipin antibody negative patients to exclude the presence of an anticoagulant. Five such patients were found in our study, including one patient with florid livedo reticularis and severe mitral valve disease and another with previous deep vein thrombosis.

Although there was a strong correlation between anticardiolipin antibody concentrations and coagulation times in our study this does not necessarily imply identity. Indeed anticardiolipin antibodies may be present in the absence of any apparent coagulation defect and in that case has less clinical significance. This study confirmed that the presence of a lupus anticoagulant was more specific for a group of patients with thrombosis or thrombocytopenia than was the presence of either IgG or IgM anticardiolipin antibodies. Furthermore, there was no significant difference in the median IgG anticardiolipin antibody concentration between IgG anticardiolipin antibody positive patients with or without a lupus anticoagulant. In those patients studied serially parallel changes in anticardiolipin antibody concentrations and coagulation times usually occurred, but there were also the occasional discordant fluctuations as has been previously noted. ${ }^{24}$ Closer concordance might be found if antibodies to anionic phospholipids other than cardiolipin were measured. Phosphatidylserine, which occurs in more abundance 
in platelet membranes, is a more likely in vivo target for an immune response, and has been shown to overcome specifically the effect of a lupus inhibitor in vitro. ${ }^{25}$

Several coagulation tests have been advocated for both screening and confirming the presence of a lupus anticoagulant. ${ }^{13-152022} 232627$ It was not the intention of this study to find the most optimal assay for either of these purposes. We chose three representative assays that could be most conveniently performed in our routine haematology tests and that between them could detect abnormalities in intrinsic (KCCT) and extrinsic (TTIT) clotting pathways. The RVVT, which is independent of both systems, is less affected by the presence of antibodies to factor VIII, IX, or $\mathrm{XI},{ }^{15}$ which have been reported to cause false positive results in the TTIT assay. ${ }^{27}$ In our hands the KCCT was the most sensitive assay and the TTIT was the most specific assay in identifying a group of patients with either thrombosis or thrombocytopenia. It is unlikely that antibodies to specific factors have influenced the results as the coagulation times did not increase during prolonged incubation and there was a high correlation between all assays used. We have not assessed more recently reported platelet neutralisation methods, which may be more specific for detecting a lupus anticoagulant. ${ }^{27}$ Until better standardisation is achieved it seems sensible for individual laboratories to use at least two assays for measuring lupus anticoagulant activity which are felt reliable under local conditions.

In summary, determination of IgG anticardiolipin antibodies by an ELISA is a good but less than perfect screening assay for the presence of a lupus anticoagulant as there are occasional patients with the anticoagulant alone. The presence of a lupus anticoagulant in anticardiolipin antibody positive patients is important as an indicator of increased specificity for antiphospholipid related events.

1 Harris E N, Gharavi A E, Boey M L, et al. Anticardiolipin antibodies: detection by radioimmunoassay and association with thrombosis in systemic lupus erythematosus. Lance 1983; ii: $1211-4$.

2 Harris E N, Asherson R A, Gharavi A E, et al. Thrombocytopenia in SLE and related autoimmune disorders: association with anticardiolipin antibodies. $\mathrm{Br} \mathcal{F}$ Haemato 1985; 59: 227-30.

3 Derue G J, Englert H J, Harris E N, et al. Fetal loss in systemic lupus erythematosus: association with anticardiolipin antibodies. Br $\mathcal{F}$ Obstet Gynaecol 1985; 5: 207-9.

4 Deleze M, Alarcon-Segovia D, Valdes-Macho E, Oria C V Ponce de Leon S. Relationship between antiphospholipid antibodies and recurrent fetal loss in patients with systemic lupus erythematosus and apparently healthy women. lupus erythematosus and appart
5 Weinstein C, Miller M H, Axtens R, Buchanan R, Littlejohn $\mathbf{G} \mathbf{O}$. Livedo reticularis associated with increased titres of anticardiolipin antibodies in systemic lupus erythematosus. Arch Dermatol 1987; 123: 596-600.

6 McHugh N J, Maymo J, Skinner R P, James I, Maddison P J. Anticardiolipin antibodies, livedo reticularis and major cerebrovascular and renal disease in systemic lupus erythematosus. Ann Rheum Dis 1988; 47: 110-15.

7 Harris E N, Chan J K H, Asherson R A, Aber V R, Gharavi A E, Hughes G R V. Thrombosis, recurrent fetal loss and thrombocytopenia: predictive value of the anticardiolipin
antibody test. Arch Inter Med 1986; 146: 2153-6.

$8 \mathrm{McHugh}$ N J, James I E, Maddison P J. Serial measurements of anticardiolipin (aCL) in connective tissue disorders. $\mathrm{Br} \mathcal{J}$ Rheumatol 1988; 27 (suppl 1): 30

9 Asherson R A. A "primary" antiphospholipid syndrome. f Rheumatol 1988; 15: 1742-6.

10 Derksen R H W M, Hasselaar P, Blokzijl L, Meyling F H J, de Groot P G. Coagulation screen is more specific than the anticardiolipin antibody ELISA in defining a thrombotic subset of lupus patients. Ann R heum Dis 1988; 47: 364-71.

11 Petri M, Golbus M, Anderson R, Whiting-O'Keefe $Q$, Corash L, Hellman D. Antinuclear antibody, lupus anticoagulant, and anticardiolipin antibody in women with idiopathic habitual abortion. Arthritis Rheum 1987; 30 : idiopa $601-6$.

12 Lockshin M D, Druzin M L, Goeli S, et al. Antibody to cardiolipin as a predictor of fetal distress or death in pregnant patients with systemic lupus erythematosus. N Engl f Med 1985; 313: 152-6.

13 Green D, Houghie C, Kaxmier F J, et al. Report of the working party on acquired inhibitors of coagulation: studies of the lupus anticoagulant. Thromb Haemost 1983; 49: 144-6.

14 Mannucci P M, Cancianni M T, Mari D, Meucci P. The varied sensitivity of the partial thromboplastin and prothrombin reagents in the demonstration of the lupus-like anticoagulant. Scand 7 Haematol 1979; 22: 423-32.

15 Thiagarajan P, Pengo V, Shapiro S S. The use of the diluted Russell viper venom time for the diagnosis of lupus Russell viper venom time for the diagn
anticoagulants. Blood 1986; 68: 869-74.

16 Tan E M, Cohen A S, Fries J F, et al. The 1982 revised criteria for the classification of SLE. Arthritis Rheum 1982 25: 1271-7.

17 Harris E N, Gharavi A E, Patel S P, Hughes G R V Evaluation of the anticardiolipin test: report of an international workshop held 4 April 1986. Clin Exp Immuno 1987; 68: 215-22.

18 Harris E N. Standardisation of the anticardiolipin test. Report of an international cooperative study The Kingston anti-phospholipid study (KAPS) group. Arthritis Rheum 1989; 32: S123.

19 Austin D E G, Rhymes I L. A laboratory manual of blood coagulation. Oxford: Blackwell Scientific, 1975.

20 Schleider M A, Nachman R L, Jaffe E A, Coleman M A clinical study of the lupus anticoagulant. Blood 1976; 48: 499-509.

21 McHugh N J, Reilly P A, McHugh L A. Pregnancy outcome autoantibodies and connective tissue disease. $\mathcal{f}$ Rheumato 1989; 16: 42-6.

22 Thiagarajan P, Shapiro S S, De Marco L. Monoclona immunoglobulin $\mathbf{M}$ lambda coagulation inhibitor with phospholipid specificity: mechanism of a lupus anticoagulant. F Clin Invest 1980; 66: 397-405.

23 Shapiro S, Thiagarajan P. Lupus anticoagulant. Prog Hemost Thromb 1982; 6: 263-85.

24 Derksen R H W M, Biesma D, Bouma B N, Gmelig Meyling F H J, Kater L. Discordant effects of prednisolone on anticardiolipin antibodies and the lupus anticoagulant. Arthritis Rheum 1986; 29: 1295-6.

25 Kelsey P R, Stevenson K J, Poller L. The diagnosis of lupus anticoagulants by the activated partial thromboplastin time-the central role of phophatidyl serine. Thromb Haemost 1984; 52: 172-5.

26 Exner T, Rickard K A, Kronenberg H. A sensitive tes demonstrating lupus anticoagulant and its behavioura patterns. Br $\mathcal{F}$ Haematol 1978; 40: 143-51.

27 Triplett D A, Brandt, J T, Kaczor D, Schaeffer J. Laboratory diagnosis of lupus inhibitors: a comparison of tissue thromboplastin inhibition procedure with a new platelet neutralization procedure. Am J Clin Pathol 1983; 79: neutralizat 